\title{
Co-Processed Excipients for Dispersible Tablets-Part 2: Patient Acceptability
}

\author{
Karolina Dziemidowicz, ${ }^{1}$ Felipe L. Lopez, ${ }^{1}$ Ben J. Bowles, ${ }^{1}$ Andrew J. Edwards, ${ }^{2}$ Terry B. Ernest, ${ }^{2}$ \\ Mine Orlu, ${ }^{1}$ and Catherine Tuleu ${ }^{1,3}$
}

Received 19 February 2018; accepted 8 June 2018; published online 25 June 2018

\begin{abstract}
Palatability and patient acceptability are critical attributes of dispersible tablet formulation. Co-processed excipients could provide improved organoleptic profile due to rational choice of excipients and manufacturing techniques. The aim of this study was to identify the most suitable co-processed excipient to use within directly compressible dispersible tablet formulations. Nine excipients, selected based on successful manufacturability, were investigated in a randomised, preference and acceptability testing in 24 healthy adult volunteers. Excipients were classified in order of preference as follows (from most preferred): SmartEx QD100 > F-Melt Type C $>$ F-Melt Type M > MicroceLac $>$ Ludiflash $>$ CombiLac $>$ Pharmaburst $500>$ Avicel HFE-102 > Avicel PH-102. Broad differences were identified in terms of acceptability, with SmartEx QD100 being 'very acceptable', F-Melt Type C, F-Melt Type M and MicroceLac being 'acceptable', Ludiflash, CombiLac and Pharmaburst 500 being 'neutral' and Avicel products being 'very unacceptable' based on ratings using five-point hedonic scales. Organoleptic differences were ascribed to different composition and physical properties of excipients, resulting in dissimilar taste and mouth-feel. Excipients with particle size in water larger than $200-250 \mu \mathrm{m}$ were considered poorly acceptable, which supports the use of this value as a threshold for maximum particle size of dispersible formulation. The most promising co-processed excipients for directly compressible dispersible tablets were successfully identified.
\end{abstract}

KEY WORDS: co-processed excipients; dispersible tablets; taste; palatability; patient acceptability.

\section{INTRODUCTION}

Co-processed excipients are the combination of two or more excipients, often prepared by spray-drying, wet granulation or co-crystallisation. They can benefit in terms of manufacturability and developability compared to traditional blends of their individual components due to the process used to prepare the combination product [1,2]. Potentially, coprocessed excipients could be used for the design and development of dispersible tablets. This delivery platform offers a solution for drug administration in paediatrics, geriatrics and patients with dysphagia, as they enable ease of administration, accurate dosing and may not require specific storage conditions compared to other pre-prepared liquid drug delivery platforms [3]. The use of this delivery

Electronic supplementary material The online version of this article (https://doi.org/10.1208/s12249-018-1104-2) contains supplementary material, which is available to authorized users.

${ }^{1}$ UCL School of Pharmacy, 29-39 Brunswick Square, London, WC1N $1 \mathrm{AX}, \mathrm{UK}$.

${ }^{2}$ GlaxoSmithKline, R\&D, Park Road, Ware, Herts, SG12 0DP, UK.

${ }^{3}$ To whom correspondence should be addressed. (e-mail: c.tuleu@ucl.ac.uk) platform in paediatrics has been widely supported as they combine advantages of both solid and liquid dosage forms [4]. Dispersible tablets often contain a large range of functional excipients, thus co-processed excipients may be advantageous by reducing the number of separate materials required within the formulation. Formulating dispersible tablets using coprocessed excipients could significantly decrease the development time of medicines indicated for patients at the extremes of age.

Patient acceptability of a medicinal product is paramount in paediatric formulations [5,6]. Patient acceptability has been defined as the 'ability and willingness of a patient to use the medicine as intended', and it is influenced by a number of parameters such as palatability, swallowability, appearance and mode of administration [7]. Palatability is considered one of the main elements affecting product's acceptability. Organoleptic profile (taste, aftertaste, mouth-feel) and dispersion time are quoted to be critical aspects when seeking regulatory approval of dispersible tablets for paediatric use [8]. As such, a dispersible tablet should disintegrate quickly in minimal aqueous media and form a homogenous dispersion with adequate palatability. Evaluation of palatability and patient acceptability should form an integral part of the pharmaceutical development studies and the Paediatric 
Investigational Plan (PIP), as recommended by the EMA [9]. Manufacturers of co-processed excipients for dispersible tablets often claim adequate organoleptic properties which may be ascribed to a rational selection of excipients and manufacturing process [10]. However, there is very scarce evidence, if any, about the organoleptic properties of these excipients.

In an initial study previously described by Bowles et al. [11], a range of co-processed excipients that are suitable for direct compression of dispersible tablet formulations were selected on the basis of manufacturability and dispersibility criteria (Fig. 1). However, sensory aspects were not evaluated despite its rising importance in drug product design. In this study, a sensory analysis was carried out using human volunteers comparing nine excipients to assess their palatability and acceptability. This sensory evaluation of excipients complements the manufacturability assessment described by Bowles et al. [11]. The aim was to identify the most promising excipient(s) to be used within directly compressible dispersible tablet formulations.

\section{MATERIALS AND METHODS}

\section{Materials}

The co-processed excipients investigated in this study were Avicel ${ }^{\circledR}$ HFE-102 (FMC biopolymers, Philadelphia, Pennsylvania, USA), CombiLac $\AA$ and MicroceLac ${ }^{\circledR}$ (Meggle Pharma, Wasserburg, Germany), F-Melt ${ }^{\circledR}$ Type $\mathrm{M}$ and FMelt ${ }^{\circledR}$ Type C (Fuji Health Science, Toyama, Japan), Ludiflash $₫$ (BASF, Lampertheim, Germany), Pharmaburst ${ }^{\circledR}$ 500 (SPI Pharma, Septemes Les Vallons, France) and SmartEx® QD100 (ShinEtsu, Tokyo, Japan). Avicel® PH102 (FMC biopolymers) was tested as a comparator against the co-processed excipients since it is a highly compressible non-co-processed excipient. All samples were kindly provided by the manufacturers. The individual constituents for each excipient are presented in Table I.

\section{Physical Characterisation of Excipients}

The particle size and shape of excipients were investigated with the aim to link physical properties and palatability, especially in terms of mouth-feel. The morphological characteristics of excipients were investigated by optical microscopy. Excipients were pre-dispersed in water $(1 \mathrm{~g}$ in $20 \mathrm{ml})$ and observed at different magnifications using an optical microscope (Evos FL, Life Technologies, Carlsbad, CA, USA) with a digital camera incorporated. The particle size distribution was assessed by laser diffraction using a Mastersizer 3000 (Malvern Scientific, Worcestershire, UK). All samples were analysed using a dry dispersion method and a wet dispersion method in aqueous media. For the dry dispersion method, the air pressure and feeding rate were individually optimised for each excipient before measurement to ensure that the obscuration was in the range of $2-6 \%$; the air pressure was 1.0 to 1.5 bargs and the feeding rate was $40-50 \%$ (Supplementary Information). For the wet dispersion method in aqueous media, approximately $1 \mathrm{~g}$ of sample was predispersed in $20 \mathrm{ml}$ of dispersant (deionised water) and then added to the dispersion accessory until the obscuration was in the range of $8-12 \%$; the sample was maintained under continuous stirring at $1500 \mathrm{rpm}$. The Mie theory was applied for the calculation of particle size for both dry and wet dispersion methods. In both cases, at least three replicates of each sample were analysed.

Particle size of powder dispersions were compared to that of tablet dispersions. Tablets were prepared as described by Bowles et al. [11]. Briefly, excipients were lubricated with $1 \% w / w$ sodium stearyl fumarate (SSF) by blending directly compressible excipients and lubricant for $2 \mathrm{~min}$ at $22 \mathrm{RPM}$ using a low shear Turbula blender (Turbula T2F, Willy A Bachofen AG Maschinenfabrik) and tablets of $10.5 \mathrm{~mm}$ diameter (round, normal concave) and $500 \mathrm{mg} \pm 5 \%$ weight were produced using a Phoenix compaction simulator (Serial no. ESH996294, Phoenix Materials Testing Ltd), adjusting the compression force to achieve a target tensile strength of 1.5 $\mathrm{MPa}$. The so-prepared tablets were dispersed in water and the particle size of the resultant dispersion was assessed by wet dispersion method, following the same methodology described above.

The proportion of insoluble material in the co-processed excipients was measured by gravimetric analysis. Accurately weighed, $1 \mathrm{~g}$ of excipient was dispersed in $10 \mathrm{ml}$ of water and the sample was swirled for approximately $1 \mathrm{~min}$ to allow dissolution of the soluble components. Subsequently, the dispersion was filtered through a $0.45-\mu \mathrm{m}$ filter by vacuum filtration. After filtration, the insoluble residue was collected from the Buchner funnel and was oven-dried at $60{ }^{\circ} \mathrm{C}$ until constant weight. The recovered insoluble material was then weighed out to calculate the insoluble particle fraction, i.e. the proportion of insoluble material with respect to the total dry weight of the excipient. The experiment was conducted in triplicate for each sample.

The fineness of dispersion tests was performed as described by Bowles et al. [11] to provide information on the mouth-feel of excipients. The compendial test establishes that the dispersion is acceptable if it passes freely through a $710-\mu \mathrm{m}$ screen. However, it has been suggested that dispersions of particle size below ca. $250 \mu \mathrm{m}$ may indicate improved mouth-feel [12]; thus, an additional sieve screen of $250 \mu \mathrm{m}$ was used in this study. For each formulation, one tablet $(500 \mathrm{mg}$ ) was immersed in $10 \mathrm{~mL}$ of water and allowed to disperse completely; the suspension was swirled to aid tablet dispersion and then poured through the sieve stack with the visual residue left on each screen being recorded.

\section{Sensory Evaluation}

Nine excipients were investigated in a single-blind, randomised, preference and acceptability testing. The study was approved by the University College London Research Ethics Committee (ERN: 4612-015) and was conducted in designated facilities at UCL School of Pharmacy. Twenty-four healthy adult volunteers were recruited for the study (aged 19-38 years, mean age $25.2 \pm 4.8$ years, $41.7 \%$ males). All participants received a detailed information sheet and provided written consent to participate in the study. The study was divided into two sessions. In session 1, panellists tested each of the nine excipients investigated, in individually randomised order, in three groups of three samples. Based on the results of session 1, the two least preferred excipients 


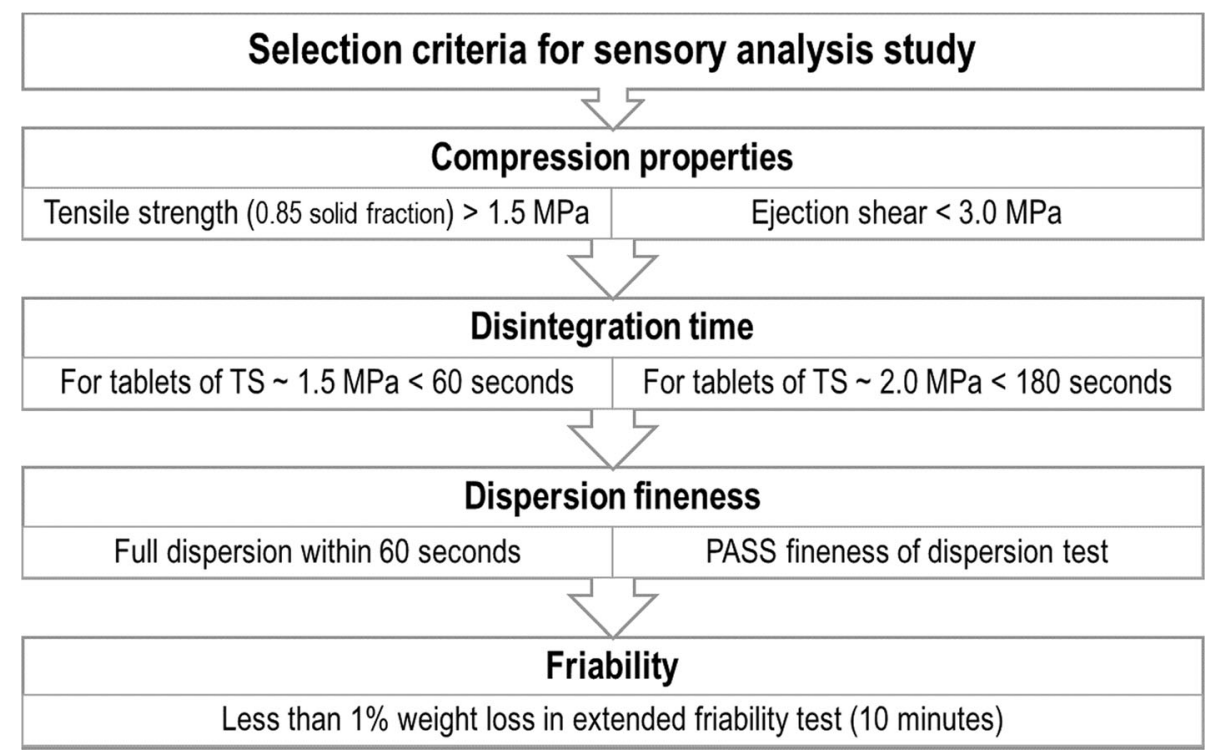

Fig. 1. Summary of criteria for selection of excipients for sensory study

were excluded for session 2 with the aim of improving discrimination between samples. Then, in session 2, panellists tested again three groups of three samples. To ensure unbiased evaluation of the samples, repeated presentation of the same excipient never occurred within each group of three samples. A balance randomisation schedule was followed to ensure that all possible combinations of three excipients were evaluated (Supplementary Information).

Test samples were prepared by dispersing $500 \mathrm{mg}$ of powder excipient in $5 \mathrm{~mL}$ of purified water. This quantity was selected considering the maximum tablet weight recommended for (oro)dispersible tablets (500 mg) [13], and the typical target dose volume for children $(5 \mathrm{ml}$ for

Table I. Individual Constituents of the Co-Processed Excipients

\begin{tabular}{|c|c|}
\hline $\begin{array}{l}\text { Excipient } \\
\text { name }\end{array}$ & Individual constituents \\
\hline Avicel PH-102 & $100 \%$ microcrystalline cellulose (reference) \\
\hline Avicel HFE-102 & $90 \%$ microcrystalline cellulose, $10 \%$ D-mannitol \\
\hline CombiLac & $\begin{array}{l}70 \% \text { alpha-lactose monohydrate, } 20 \% \\
\text { microcrystalline cellulose, } 10 \% \text { native } \\
\text { corn starch }\end{array}$ \\
\hline F-Melt Type C & $\begin{array}{l}55-70 \% \text { D-mannitol, } 10-25 \% \text { microcrystalline } \\
\text { cellulose, 2-9\% xylitol, } 5-13 \% \text { crospovidone, } \\
2-9 \% \text { dibasic calcium phosphate anhydrous }\end{array}$ \\
\hline F-Melt Type M & $\begin{array}{l}55-70 \% \text { D-mannitol, } 10-25 \% \text { microcrystalline } \\
\text { cellulose, 2-9\% xylitol, } 5-13 \% \text { crospovidone, } \\
2-9 \% \text { magnesium aluminometasilicate }\end{array}$ \\
\hline Ludiflash & $\begin{array}{l}90 \% \text { D-mannitol, } 5 \% \text { crospovidone, } 5 \% \\
\text { polyvinyl acetate (PVAc) dispersion }\end{array}$ \\
\hline MicroceLac & $\begin{array}{l}75 \% \text { alpha-lactose monohydrate, } 25 \% \\
\text { microcrystalline cellulose }\end{array}$ \\
\hline Pharmaburst 500 & $\begin{array}{l}85 \% \text { D-mannitol, }<10 \% \text { silicon dioxide } \\
<10 \% \text { sorbitol, } 5 \% \text { crospovidone }\end{array}$ \\
\hline SmartEx QD 100 & $\begin{array}{l}\text { D-mannitol, polyvinyl alcohol } \\
\text { (PVA), low-substituted hydroxypropyl } \\
\text { cellulose (L-HPC) }\end{array}$ \\
\hline
\end{tabular}

children under 5 years) [14]. The untrained panellists were provided three different blind samples at a time, up to a total of nine samples. They were instructed to invert the sample to ensure homogenous dispersion of the excipients and then taste the sample by swirling the contents in the mouth for 10-20 s before spitting the sample into a receptacle provided. Participants had free access to spring water and unsalted crackers and were instructed to cleanse their palate before each sample. Subject-reported outcomes were recorded after evaluation of each group of three samples using an online structured questionnaire. Participants were asked to rank the samples in order of their preference (forced-choice preference, no ties allowed). The volunteers were also asked to assign a key attribute (appearance, mouth-feel, taste, cooling sensation, smell) that contributed to the ranking selection. Acceptability was evaluated using five-point hedonic scales (anchored from (1) 'very acceptable' to (5) 'very unacceptable'). An open-ended comment section was implemented to obtain a qualitative response.

\section{Statistical Analysis}

For data analysis, samples were assigned numerical values based on subject-reported preference in each group of three samples $(-1,0,+1$, from least to most preferred sample) and results of hedonic scales were assigned numerical values from 1 (extremely acceptable) to 5 (extremely unacceptable). Results from session 1 and session 2 were compared and, given the negligible differences, analysis was carried on pooled data from both sessions. Statistical analysis was performed using the non-parametric Kruskal-Wallis one-way analysis of variance followed by Dunn's test as post hoc test for pairwise comparison, both with a 95\% confidence level. Association between physical properties of the excipients and hedonic ratings provided by volunteers was investigated using the chi-square test for association with $95 \%$ confidence level. 


\section{RESULTS AND DISCUSSION}

\section{Summary of Manufacturability Properties of Excipients}

The nine excipients selected for investigation in this study were those that showed the best results in terms of manufacturability as presented by Bowles et al. [11]. A summary of in vitro tests conducted on the excipients selected for the palatability study is presented in Table II. All formulations showed good compression properties, low ejection shear $(\leq 2.63 \mathrm{MPa})$ at target tensile strengths of $1.5 \mathrm{MPa}$ and friability less than or equal to 0.25 and $0.82 \%$ over 4 and 10 min respectively.

The excipients selected in this study produced tablets that have a disintegration time of less than $60 \mathrm{~s}$. This is an important attribute of dispersible tablets, as it is related to patient acceptability, requiring a prompt disintegration in minimal liquid for convenient administration. Another attribute of dispersible tablets related to the patient acceptability is fineness of dispersion, typically investigated by dispersing a tablet in $100 \mathrm{~mL}$ of purified water which is then passed through a $710-\mu \mathrm{m}$ sieve [15]. However, Bowles et al. investigated both 710 and $250 \mu \mathrm{m}$ sieves with a smaller volume of water $(10 \mathrm{ml})$ to resemble in-use conditions and to increase discrimination between the different excipients [11]. The $250-\mu \mathrm{m}$ sieve was used to determine if the sensory analysis study using human volunteers identified similar trends to the in vitro results with the aim to identify a possible additional test to provide in vitro sensory information and help differentiate between formulations. All formulations passed the fineness of dispersion test through the $710-\mu \mathrm{m}$ sieve, except for Avicel PH-102, as supported by previous research [16]. Grittiness perception is expected for Avicel $\mathrm{PH}-102$, which was used as a control in the palatability study since it is a common dispersible tablet (non-coprocessed) excipient. Avicel PH-102, Avicel HFE-102 and Pharmaburst 500 all failed to pass through the $250 \mu \mathrm{m}$ sieve, which could be explained by the presence of insoluble material coarser than $250 \mu \mathrm{m}$, including swollen particles and agglomerates. This could indicate poor mouth-feel compared to those excipients which passed through the $250-\mu \mathrm{m}$ sieve.

\section{Physical Characterisation of Excipients}

The perception of a powder in the mouth is dependent on physical properties, including solubility, particle size and concentration of the dispersed particles $[17,18]$. Therefore, it was hypothesised that the particle morphology will influence the palatability of tested samples, particularly in terms of mouth-feel.

The morphological characteristics of the co-processed excipients when dispersed as powders in water were investigated by optical microscopy (Fig. 2). Avicel PH102 is a pure, water-insoluble microcrystalline cellulose (MCC) excipient, characterised by irregular fibres which agglomerate in aqueous environment $[19,20]$. Similarly, the micrograph of Avicel HFE-102 showed the irregular structures of MCC, which might be expected to elicit rough mouth-feel. The micrographs of F-Melt Type $\mathrm{C}$ and F-Melt Type $M$ presented almost identical irregular particles, possibly composed of a mixture of MCC plus the insoluble calcium and magnesium compounds present in their composition, respectively. It is likely that the particles present in CombiLac and MicroceLac were also MCC fibres, since lactose is soluble in water; CombiLac micrographs also revealed small rounded particles attributable to starch [21]. Agglomeration of MCC particles was more pronounced in Avicel products than in other excipients, which can be explained by the greater concentration of MCC in the former [22]. Ludiflash, Pharmaburst and SmartEx QD100 are largely composed of the watersoluble mannitol; thus, the particles shown in the optical micrographs can be ascribed to insoluble materials, such as polyvinyl acetate in Ludiflash, silicon dioxide in Pharmaburst and swollen hydroxypropyl cellulose and/or polyvinyl alcohol in SmartEx QD100.

The particle size distribution of the investigated excipients is presented in Table III. All co-processed excipients had comparable particle size in dry form, with a median particle size between 81 and $125 \mu \mathrm{m}$. When the powder excipients were dispersed in water, Avicel HFE-102 and Avicel PH-102 exhibited an increase in size with respect to the particle size measured by dry dispersion $\left(\mathrm{D}_{50}\right.$ increased 25.9 and $17.1 \%$, respectively); such increase was attributed to moderate swelling of the insoluble MCC, which is well known for its

Table II. In Vitro Tests Results for Co-Processed Excipients Selected for Sensory Analysis Study

\begin{tabular}{|c|c|c|c|c|c|c|c|}
\hline \multirow[t]{2}{*}{ Co-processed excipient } & \multirow[t]{2}{*}{ Tensile strength $(\mathrm{MPa})$} & \multirow[t]{2}{*}{ Ejection shear (MPa) } & \multicolumn{2}{|l|}{ Friability } & \multirow[t]{2}{*}{ Disintegration time (s) } & \multicolumn{2}{|c|}{ Dispersion fineness } \\
\hline & & & $\% 4 \min$ & $\% 10 \min$ & & $710 \mu \mathrm{m}$ & $250 \mu \mathrm{m}$ \\
\hline Avicel PH-102 & 1.47 & 1.04 & 0.03 & 0.11 & 38 & Fail & Fail \\
\hline Avicel HFE-102 & 1.48 & 1.00 & 0.02 & 0.11 & 35 & Pass & Fail \\
\hline CombiLac & 1.49 & 1.79 & 0.06 & 0.30 & 42 & Pass & Pass \\
\hline F-Melt Type C & 1.50 & 0.57 & 0.06 & 0.19 & 30 & Pass & Pass \\
\hline F-Melt Type M & 1.43 & 1.74 & 0.04 & 0.21 & 28 & Pass & Pass \\
\hline Ludiflash & 1.45 & 2.16 & 0.21 & 0.72 & 47 & Pass & Pass \\
\hline MicroceLac & 1.59 & 2.28 & 0.02 & 0.12 & 44 & Pass & Pass \\
\hline Pharmaburst 500 & 1.43 & 0.64 & 0.25 & 0.55 & 27 & Pass & Fail \\
\hline SmartEx QD100 & 1.55 & 2.63 & 0.18 & 0.82 & 27 & Pass & Pass \\
\hline
\end{tabular}




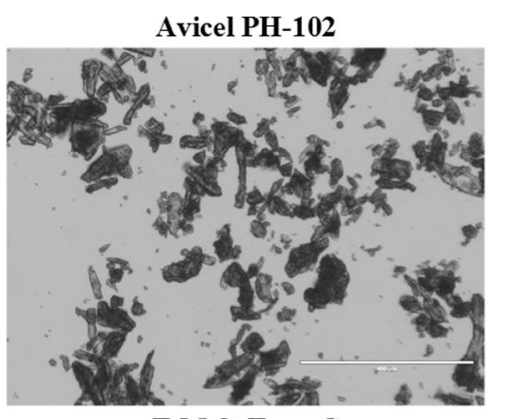

F-Melt Type C

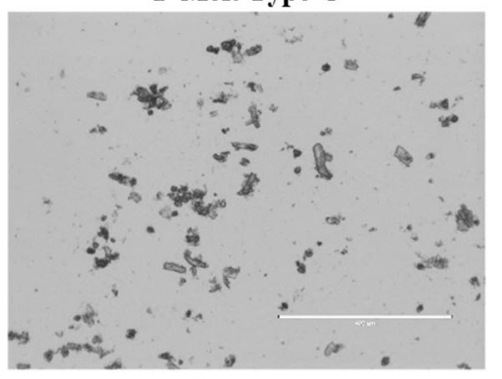

MicroceLac

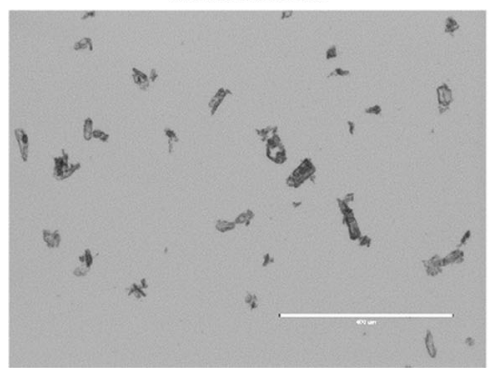

Fig. 2. Optical microscopy images of the co-processed excipients (powder dispersed in water) at $\times 10$ magnification (scale bar $400 \mu \mathrm{m})$

swelling propensity in aqueous or high-humidity environments $[23,24]$. In contrast, all other excipients suffered a size reduction, which can be explained by dissolution of the watersoluble components in the formulation; the reduction in median particle size ranged between -43.1 and $-72.5 \%$. Although wet dispersion particle size analysis is usually performed under the assumption that the particles being measured do not dissolve in the continuous phase, components of the excipients may be suspended, dissolved and/or swelled under the conditions selected for this study where water was used as dispersant [25]. This methodology was employed to understand the particle size of excipients in water, since this is the standard administration vehicle for dispersible tablets.

Since dispersible tablets are pre-dispersed in water before administration, the particle size measured by wet

Table III. Particle Size Distribution of Co-Processed Excipients Measured by Laser Diffraction Following Dry and Wet (Water) Dispersion Methods. Average of Three Measurements (Relative Standard Deviation, \%)

\begin{tabular}{|c|c|c|c|c|c|c|c|c|c|}
\hline \multirow[t]{2}{*}{ Co-processed excipient name } & \multicolumn{3}{|c|}{ Powder dry dispersion $(\mu \mathrm{m})$} & \multicolumn{3}{|c|}{ Powder wet dispersion $(\mu \mathrm{m})$} & \multicolumn{3}{|c|}{ Size difference $(\%)^{\mathrm{a}}$} \\
\hline & D10 & D50 & D90 & D10 & D50 & D90 & D10 & D50 & D90 \\
\hline Avicel PH-102 & $37(0.7)$ & $112(0.1)$ & $234(0.3)$ & $51(0.6)$ & $141(0.6)$ & $278(0.7)$ & 37.8 & 25.9 & 18.8 \\
\hline Avicel HFE-102 & $36(0.4)$ & $117(0.5)$ & $234(0.3)$ & $45(0.1)$ & $137(0.9)$ & $262(0.8)$ & 25.0 & 17.1 & 12.0 \\
\hline CombiLac & $36(2.2)$ & $115(2.5)$ & $246(0.9)$ & $9(0.3)$ & $32(0.5)$ & $101(0.7)$ & -76.2 & -72.5 & -58.9 \\
\hline F-Melt type C & $37(2.8)$ & $108(2.4)$ & $217(2.8)$ & $11(1.4)$ & $44(2.0)$ & $105(2.0)$ & -71.6 & -59.4 & -54.5 \\
\hline F-Melt type M & $44(3.0)$ & $111(6.0)$ & $211(5.5)$ & $11(1.3)$ & $46(1.6)$ & $103(1.3)$ & -74.8 & -58.7 & -51.2 \\
\hline Ludiflash & $25(1.9)$ & $121(2.3)$ & $278(8.8)$ & $13(0.7)$ & $56(1.1)$ & 145 (1.6) & -48.0 & -53.7 & -47.8 \\
\hline MicroceLac & $39(3.7)$ & $125(4.0)$ & $249(2.3)$ & $9(1.2)$ & $38(1.5)$ & $103(1.0)$ & -78.0 & -69.8 & -58.6 \\
\hline Pharmaburst 500 & $23(4.7)$ & $98(3.4)$ & 199 (1.1) & $18(3.5)$ & $54(0.5)$ & $106(0.5)$ & -22.6 & -45.1 & -46.7 \\
\hline SmartEx QD100 & $36(1.2)$ & $94(3.2)$ & $200(4.3)$ & $19(0.3)$ & $54(0.4)$ & $110(0.5)$ & -46.1 & -43.1 & -45.0 \\
\hline
\end{tabular}

\footnotetext{
${ }^{a}$ Difference in particle size distribution between dry and wet dispersion methods expressed as percentage
} 
dispersion in water can provide relevant information of the mouth-feel of excipients. Based on previous studies with orodispersible tablets, rough mouth-feel is expected to be pronounced for particles larger than 200-250 $\mu \mathrm{m}$ [12]. Avicel HFE-102 and Avicel PH-102 exhibited relatively larger particle size than other excipients, with a $\mathrm{D}_{50}$ larger than $100 \mu \mathrm{m}$ and $\mathrm{D}_{90}$ larger than $200 \mu \mathrm{m}$. On the contrary, all other excipients showed a $\mathrm{D}_{50}$ below $60 \mu \mathrm{m}$ and $\mathrm{D}_{90}$ below $150 \mu \mathrm{m}$ when dispersed in water. These findings were in line with the optical microscopy images which evidenced that Avicel products had coarser particle size than other excipients in aqueous media. The particle size of co-processed excipients measured by wet dispersion in water is depicted in Fig. 3.

The particle size of powder dispersions in water was compared to that of tablet dispersions in water (i.e. tablets prepared at $1.5 \mathrm{MPa}$ and subsequently dispersed in water) to assess the potential effect of compression on the particle size of excipients. The particle size distribution of excipients before and after compression was very comparable, the median particle size of powder dispersion being within $10 \%$ difference of that of the tablet dispersions (Supplementary Information). The negligible differences found between the particle size of powder excipients and their corresponding tablets justified the use of powders instead of tablets for the sensory evaluation analysis.

The amount of the insoluble material after dispersion of a tablet in water may impact palatability of the product upon administration. The residue of insoluble material in the mouth has been recognised as an important parameter in acceptability of (oro)dispersible formulations [26]. The insoluble particle fraction (i.e. the proportion of insoluble material) in the co-processed excipients was calculated by gravimetric analysis, and results are shown in Fig. 4. Large differences were found between co-processed excipients, with Avicel HFE-102 showing the greatest proportion of insoluble material $(87.9 \%)$ and SmartEx QD100 the smallest insoluble particle fraction (5.1\%). Most of the co-processed excipients however had less than $30 \%$ insoluble components, with the only exception of Avicel HFE-102.

\section{Overview of Forced-Choice Ranking and Hedonic Ratings}

The results of the forced-choice ranking comparison are presented in Fig. 5, where the excipients are shown in order of preference, from most preferred to least preferred. Overall, the top performer was SmartEx QD100, which was selected as the most preferred excipient in $90 \%$ of the occasions when compared against two other randomly selected candidates. Moreover, SmartEx QD100 was the only excipient not selected as the least preferred sample when compared against two other randomly selected candidates by any of the participants. F-Melt Type C and F-Melt Type M completed the top-3 most preferred excipients, followed by MicroceLac, Ludiflash, CombiLac and Pharmaburst 500. Avicel HFE-102 and Avicel PH-102 were identified as the least preferred excipients, significantly ranked as the least preferred option by more than 80 and $90 \%$ of participants, respectively.

Participants were also asked to describe the overall acceptability of the samples using a five-point facial hedonic scale. Figure 5 presents the comparison of hedonic ratings, where 1 corresponds to 'very acceptable' and 5 to 'very unacceptable'. SmartEx QD100 seemed to be a very acceptable excipient, with a median rating of 1 , and was significantly better than any of the other excipients tested. This was followed by F-Melt Type C, F-Melt Type M and MicroceLac, all with a median rating of 2, which suggests that these excipients were also acceptable. Ludiflash, CombiLac and Pharmaburst, with a median rating of 3 , were considered neutral in terms of acceptance. Finally, Avicel HFE-102 and $\mathrm{PH}-102$, with median rating of 5, were rated significantly worse than any of the other excipients. Overall, the results of hedonic ratings were in close agreement with the forcedchoice rank ordering.

From those who ranked SmartEx QD100 as their most preferred excipient, $49 \%$ suggested that the taste of the dispersion was the 'key attribute' that contributed to their ranking and $44 \%$ referred to the mouth-feel of the sample as the main reason behind their choice, whereas the remaining $7 \%$ reported that the clear appearance of the dispersion was the most important attribute. As such, a balance between

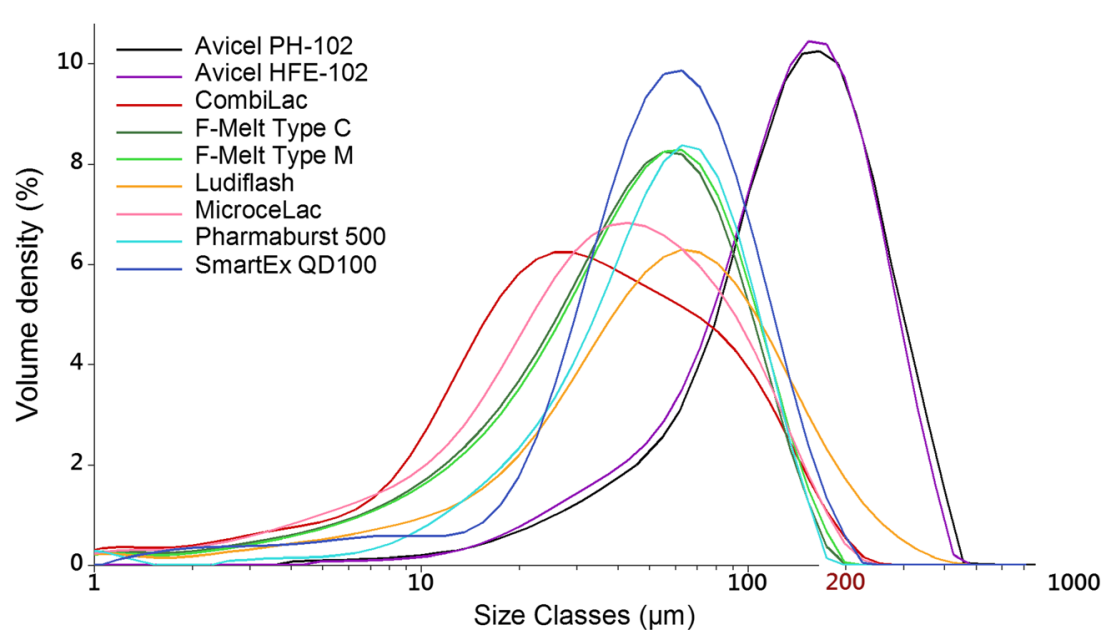

Fig. 3. Particle size distribution of co-processed excipients (powders dispersed in water) evaluated by laser diffraction in wet dispersion using water as dispersant 


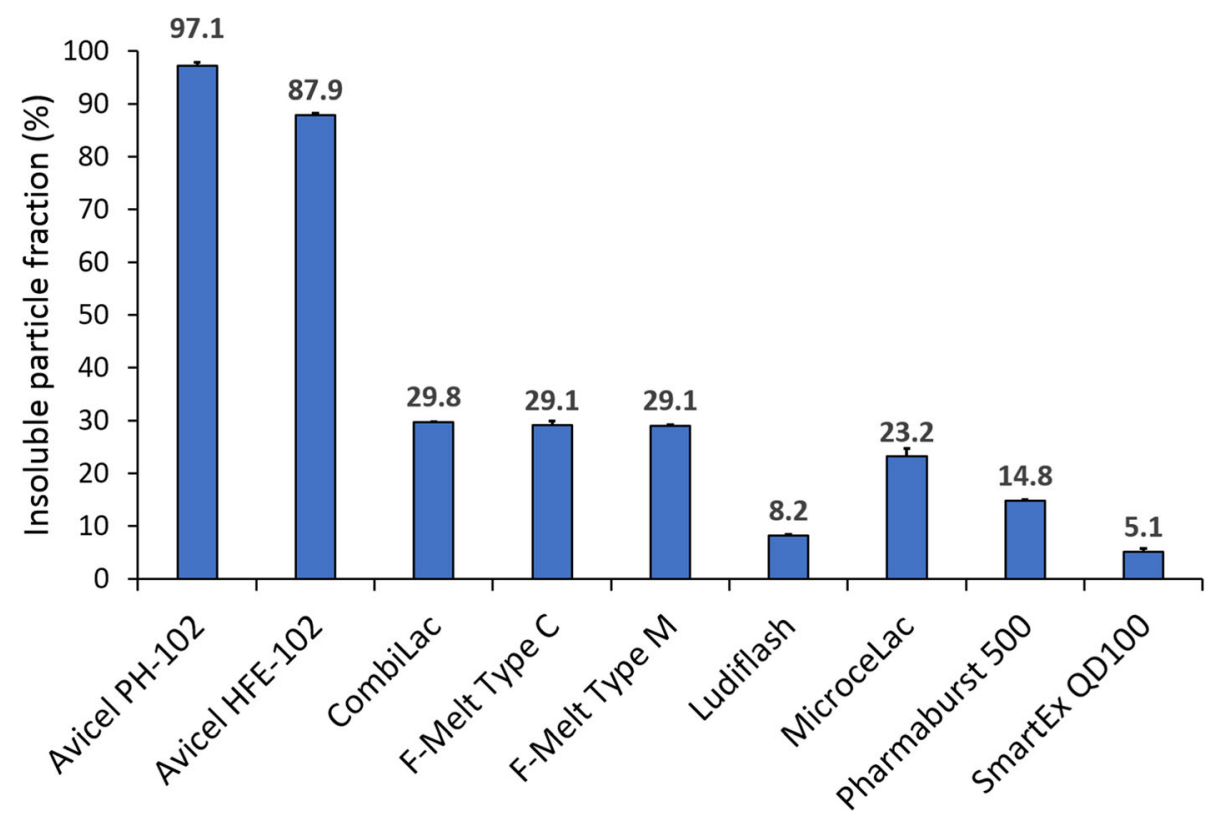

Fig. 4. Insoluble particle fraction of excipients calculated by gravimetric analysis after excipient dispersion and dissolution of soluble components in water at a concentration of $500 \mathrm{mg} / 5 \mathrm{ml}(N=3)$

taste and mouth-feel seemed to drive participants' perceptions of the appropriate organoleptic properties of SmartEx QD100. However, from those participants who ranked Avicel HFE-102 and Avicel PH-102 as their least preferred samples, an overwhelming majority referred to mouth-feel as the key attribute for their choice (95 and 91\%, respectively). The rough mouth-feel from Avicel products was expected because of the large $(>200 \mu \mathrm{m})$, irregular MCC particles that were identified during morphological characterisation of the samples. Overall, taste and mouth-feel were most commonly selected as key palatability attributes, whereas cooling sensation, smell and appearance were less significant. All the positive and negative key attributes for each excipient are provided in Supplementary Information.

\section{Individual Analysis of Co-Processed Excipients Based on the Hedonic Rating}

The individual hedonic ratings calculated from data collected in both sensory analysis sessions are presented in Fig. 6. SmartEx QD100 received remarkably positive responses, with no negative votes and over $65 \%$ of highest marks for hedonic ratings. The exact composition of SmartEx QD100 has not been published by the manufacturer, but it is known to contain mannitol (filler), polyvinyl alcohol (binder) and L-HPC (disintegrant). The overall success of SmartEx QD100 is also reflected in the open-ended comments provided by the volunteers. The dispersion of this excipient was described as 'sweet', 'smooth', 'clear' or 'least powdery'. The relatively small particle size $\left(D_{50}\right.$ in wet dispersion $=54$ $\mu \mathrm{m})$, quick dispersion and dissolution into a clear and visually appealing liquid and the presence of mannitol could be responsible for a highly favourable mouth-feel and sweet taste. Palatability and manufacturability results show promising future for the utilisation of SmartEx QD100 in directly compressible dispersible tablet formulations.
The second and third highest scores in hedonic ratings were observed for F-Melt Type C and F-Melt Type M, with 69.8 and $65.0 \%$ positive ratings respectively, both being statistically equivalent. The composition of these excipients is the same except for one component. F-Melt Type C contains dibasic calcium phosphate anhydrous (DCPA) (Fujicalin ${ }^{\circledR}$ ), and F-Melt Type M contains spherical particles of magnesium aluminometasilicate (Neusilin $\left.{ }^{\circledR}\right)$. The generally acceptable palatability of F-Melt in fast disintegrating tablets was previously attributed to the presence of mannitol in the composition [27]. In this study, participants described F-Melt products as being 'moderately sweet' and having 'smooth' texture. Interestingly, these excipients contain 10$25 \%$ of microcrystalline cellulose, but the presence of this insoluble excipient did not affect the overall palatability. The particle size of MCC in F-Melt products is controlled by the spray-drying process and was smaller than that of Avicel PH102, which explains why F-Melt products were more palatable. In addition, MCC is less likely to agglomerate in F-Melt products, since it is incorporated with water-soluble excipients in spherical spray-dried particles and is present at lower concentration than in Avicel products [22].

Ludiflash and Pharmaburst 500 performed comparatively worse than the other mannitol-based co-processed excipients investigated in this study. Although the taste of Ludiflash was considered to be neutral, with participants describing it as 'almost tasteless' and 'slightly sweet', some volunteers described this excipient as 'grainy' and 'coarse'. The coarse feeling in the mouth perceived by some participants could be ascribed to polyvinyl acetate (PVAc), since this is the only non-water-soluble component in Ludiflash. Ludiflash exhibited the third largest particle size $\left(\mathrm{D}_{90}=148 \mu \mathrm{m}\right)$ from the excipients investigated, after Avicel PH102 and HFE-102, which supports the results of the in vivo sensory evaluation. However, the supplier claims that Ludiflash does not cause a chalky or sandy sensation in the mouth but rather a pleasant and creamy mouth-feel, despite the presence of relatively 

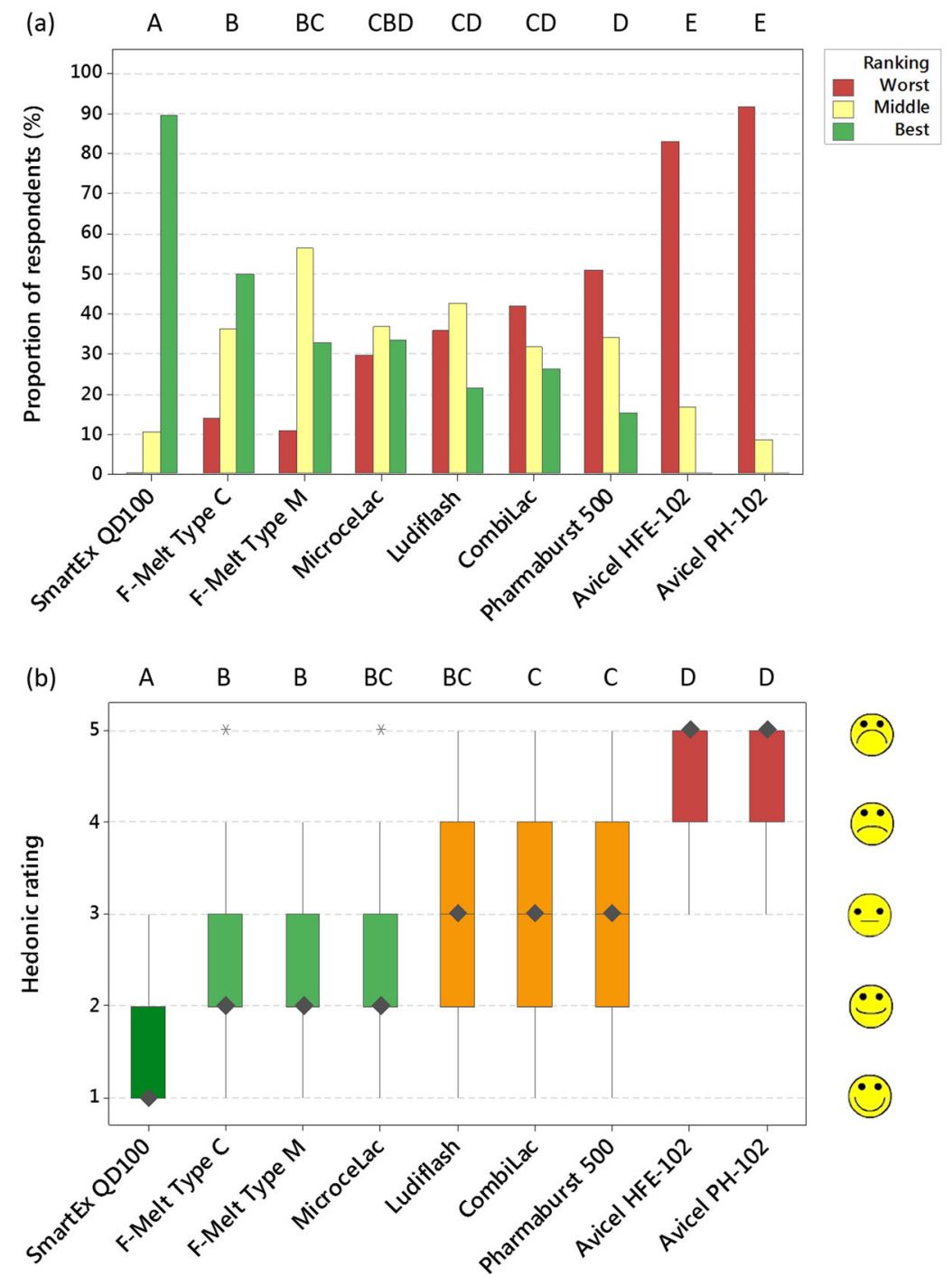

Fig. 5. a Forced-choice ranking order results shown as proportion of participants who selected each excipient as being the 'best', 'middle' or 'worst' within randomised combinations of three excipients. b Box plot of hedonic ratings where markers show the median; box limits indicate the interquartile range and outliers are denoted by asterisks. Excipients which do not share a letter can be considered significantly different based on Kruskal-Wallis test with $95 \%$ confidence

large particles [28]. Nevertheless, Ludiflash obtained 73.2\% of neutral-positive ratings, which suggests a rather positive organoleptic profile. In the case of Pharmaburst 500, the proportion of volunteers providing negative ratings on the hedonic scale $(48.9 \%)$ exceeded those providing positive ratings $(26.7 \%)$. Interestingly, the high polyol concentration $(73.8-93.8 \% w / w)$ did not result in a highly favourable organoleptic profile, despite the pleasant taste and mouthfeel often attributed to mannitol [28-30]. Participants reported mouth-feel $(60 \%)$, followed by taste $(26 \%)$ and smell $(14 \%)$, as the key attributes for the negative evaluation of Pharmaburst 500. The presence of the poorly soluble silicon dioxide particles could have negatively influenced the overall organoleptic profile of this excipient [31]. This excipient still showed a favourable organoleptic profile compared to pure MCC, as supported by previous research [32].

MicroceLac and CombiLac were the only lactose-based co-processed excipients tested in this study. Lactose has been widely used as a filler in pharmaceutical preparations for many years thanks to its low cost, good flow characteristics and disintegration by dissolution [33]. Recently, its popularity has declined in favour of mannitol [30] due to highly reported adverse reactions associated with lactose intolerance [34] and the risk of API-excipient interaction caused by the Maillardreaction [35]. The additional constituents of these coprocessed excipients are MCC (for both) and corn starch (in CombiLac). Starch, as a viscosity-modifying excipient, is often used to promote physical stability of dispersions while enhancing their organoleptic profile by creating a smooth, creamy mouth-feel [36]. In contrast, CombiLac performed worse than MicroceLac, despite the inclusion of starch in the former compared to the latter. The anecdotal responses described the taste of CombiLac as 'plain' and 'slightly unpleasant' and noticed the grittiness in the sample possibly caused by the presence of MCC [16]. Excessive swelling of excipients (such as starch and MCC) could also be 

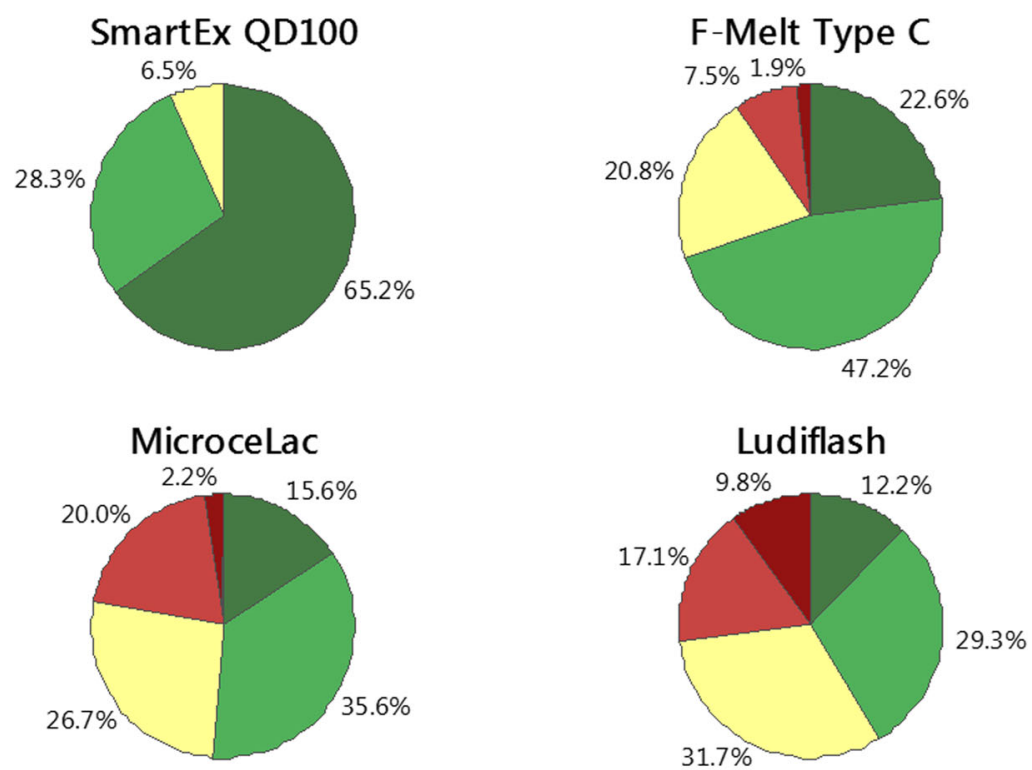

Avicel HFE-102
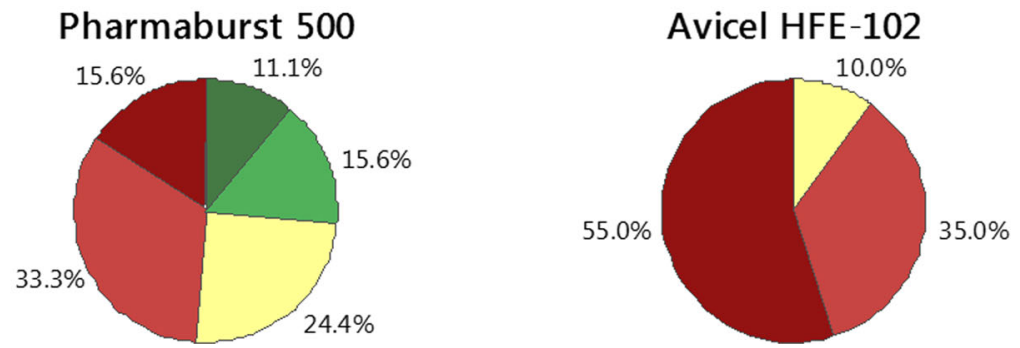
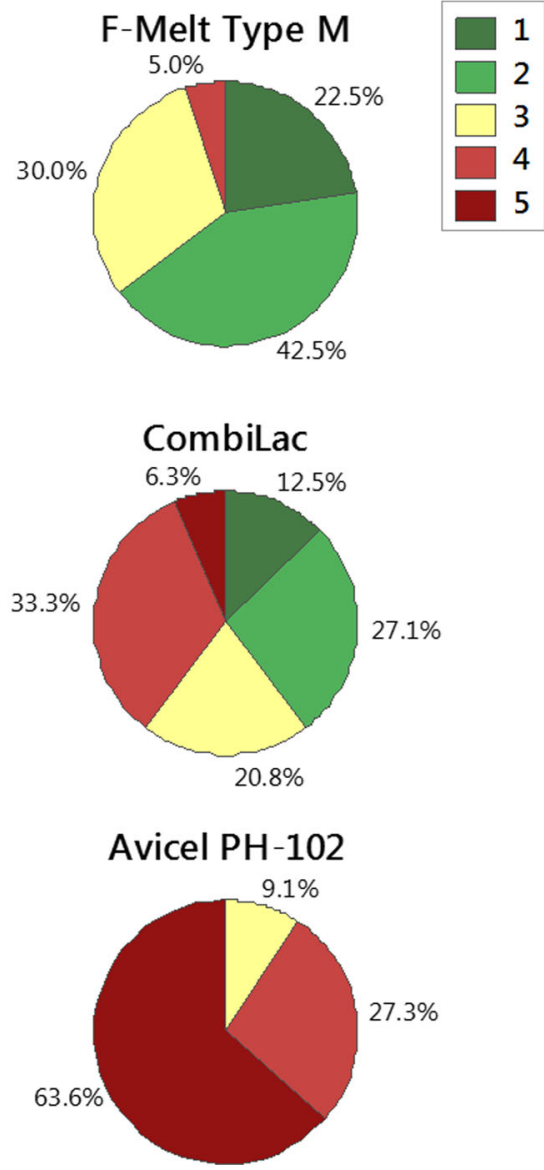

Fig. 6. Overall hedonic rating for each excipient. The five-point hedonic scale was used (1-very acceptable, 2-acceptable, 3-neutral, 4-unacceptable, 5-very unacceptable)

responsible for the unpleasant mouth-feel, as suggested by previous research [16]. However, both MicroceLac and CombiLac received over $60 \%$ of neutral-positive responses and could be suitable excipients for dispersible tablets.

Avicel HFE-102 was the least acceptable co-processed excipient tested in this study. Avicel HFE-102 is composed of $90 \%$ MCC which is co-spray-dried with $10 \%$ mannitol. A previous review reported that the presence of this polyol improves palatability of the product by conferring sweet taste and a cooling effect [2]. This study however showed that the organoleptic profile of Avicel HFE-102 was comparable to that of pure MCC (Avicel PH-102) and significantly worse than that of other co-processed excipients. The rough mouthfeel of this excipient can be explained by the large proportion and coarse size of the insoluble MCC particles $\left(D_{50}\right.$ in water dispersion $=137 \mu \mathrm{m})$.

Avicel PH-102 is solely based on MCC and was used as a control in this study since it is a non-co-processed excipient commonly used in dispersible tablet formulations with wellestablished good compression properties but poor mouthfeel. This excipient was negatively perceived by the volunteers of the present study, who described the mouth-feel as 'sandy' or 'chalky' and the taste as 'neutral' or 'bland'. Avicel $\mathrm{PH}-102$ is currently included in a wide range of paediatric medicines, such as dispersible tablets, chewable tablets and powders for oral suspension [37]. This study demonstrated that co-processed excipients can be a suitable alternative for dispersible tablets prepared by direct compression, providing improved palatability compared to pure MCC.

\section{The Link between Physical Properties of Excipients and Palatability}

Palatability can be defined as the overall appreciation of an oral product in relation to its appearance, smell, taste, aftertaste and feeling in the mouth [8]. Results of this study indicate that both taste and mouth-feel were the most important criteria for acceptability of excipients intended for dispersible tablet formulations. This is consistent with previous studies which suggested that taste, mouth-feel and dose volume (in that order) are the most important drivers for the acceptability of medicines [26,38]. Some of the co-processed excipients include sweeteners, such as mannitol, xylitol or sorbitol, to improve the taste of the resulting dispersion. The sweet taste, adequate mouth-feel and negative heat of solution that imparts a cooling sensation in the mouth are attributes of mannitol which are well-established in the scientific literature [28-30]. Mouth-feel can be influenced by the physical properties of the excipients, including solubility, particle size and concentration of particles [17,18]. Coprocessed excipient manufacturers often claim adequate texture and mouth-feel of their products based on rational selection of ingredients and manufacturing process [2]. The texture of pharmaceutical products has been previously 
assessed by in vitro methods including texture analysis and tribology [26,39].

In the present study, a modified version of the compendial fineness of dispersion test was employed as a simple and expedited approach to estimate the texture of excipients [11]. Interestingly, an association between the fineness of dispersion test using a $250-\mu \mathrm{m}$ sieve and palatability outcomes was found in the present study. Pharmaburst, Avicel HFE-102 and Avicel PH-102 were the only excipients in this study to fail the $250-\mu \mathrm{m}$ fineness of dispersion test and were selected as the least preferred and least acceptable excipients. The association between fineness of dispersion through $250 \mu \mathrm{m}$ sieve and hedonic ratings of acceptability was statistically significant $(p<0.001)$. Other parameters which provided an indication of mouth-feel include particle size in wet dispersion and amount of insoluble materials in the formulation. The negative effect of insoluble particle fraction and particle size on acceptability was significant $(p<0.001)$. Both particle size and insoluble particle fraction can be expected to affect fineness of dispersion which, in turn, will affect mouth-feel and overall palatability [16].

Particle size distribution analysis confirmed the relatively large particle size of Avicel products, which explains why these excipients failed the fineness of dispersion test and were poorly palatable. In other cases, the link between in vitro and in vivo results was not that obvious. Pharmaburst 500 is mainly based on water-soluble mannitol and its dispersion in water exhibited a small particle size $(\mathrm{D} 50=54 \mu \mathrm{m})$, comparable to excipients such as SmartEx QD100 which passed the fineness of dispersion test. It could be hypothesised that agglomeration of particles in suspension was responsible for the negative fineness of dispersion test result of Pharmaburst 500 and its relatively poor organoleptic profile. The residue produced by Pharmaburst 500 on the $250-\mu \mathrm{m}$ mesh was much less significant than that produced by Avicel PH-102 (as shown in the images in Supplementary Information), which explains the better palatability of the former. Meanwhile, Ludiflash passed the fineness of dispersion test despite its relatively large particle size, which might be explained by the small amount of insoluble material (ca. 8\%) and other physical properties not considered in this study, such as stickiness of the dispersion.

Palatability and acceptability are influenced by characteristics of the medicinal product (e.g. taste, mouth-feel, volume, appearance) and characteristics of the end-user (e.g. age, ability, disease type and state) [9]. Ideally, evaluation of palatability and acceptability must consider all product factors holistically $[6,40]$. In this regard, human panels continue to be the gold standard to assess palatability [41]. Previous attempts to predict palatability based on physical properties of excipients resulted in poor predictive power due to the difficulty to consider all contributing factors [26]. Nevertheless, a range of studies have linked physical properties of materials, such as particle size, shape, residue in the mouth, concentration of particles, sample volume and viscosity of the media with oral texture perception of the product $[12,17,18,26,42-44]$. The present study suggests that in vitro tests such as particle size analysis, insoluble particle fraction and fineness of dispersion test can provide an indication of palatability of excipients, especially in terms of mouth-feel.
Due to the inherent differences in taste preferences between different subsets of the population [45], this study should be extended to paediatrics and geriatrics, those who could benefit most from dispersible tablet formulations.

\section{CONCLUSION}

This study provided a screening of co-processed excipients commonly used in dispersible tablet formulations based on their palatability. The sensory analysis of co-processed excipients revealed significant differences in their organoleptic profiles. SmartEx QD100 was the most palatable out of eight co-processed excipients tested, followed by F-Melt Type C, F-Melt Type M, MicroceLac (considered to have acceptable palatability), Ludiflash, CombiLac and Pharmaburst (with neutral palatability). Avicel HFE-102 was the least acceptable due to large and water-insoluble particles that resulted in a gritty mouth-feel. In general, co-processed excipients exhibited a positive organoleptic profile compared to pure MCC (Avicel PH-102), which was used as a control. Evaluation of particle size, insoluble particle fraction and fineness of dispersion with a modified compendial method appear to be related to the palatability of the excipients because of their likely impact on mouth-feel. Excipients with particle size in water larger than 200-250 $\mu \mathrm{m}$ were considered poorly acceptable, which supports the use of this value as a threshold for maximum particle size of dispersible formulation.

This work is part of a broader investigation aimed at the assessment of co-processed excipients based on their manufacturability (Part 1, [11]) and end-user acceptability (Part 2). Overall, the most promising excipient platforms for the development of dispersible tablets by direct compression has been identified among a range of co-processed excipients. SmartEx QD100 and F-Melt Type C have been established within the top 3 excipients in terms of manufacturability and acceptability, which makes them the most promising candidates for dispersible tablets. However, this study does not preclude the need to evaluate manufacturability and patient acceptability of directly compressible dispersible tablets during pharmaceutical development studies, as the API properties will greatly affect manufacturability and patient acceptability.

\section{ACKNOWLEDGEMENTS}

The authors would like to thank all excipients suppliers for kindly providing samples.

Funding Information This work was supported by the CDT in Targeted Therapeutics and Formulation Sciences (EP/I01375X/1) and the CDT in Advanced Therapeutics and Nanomedicines (EP/L01646X), which are funded by the EPSRC.

Open Access This article is distributed under the terms of the Creative Commons Attribution 4.0 International License (http://creativecommons.org/licenses/by/4.0/), which permits unrestricted use, distribution, and reproduction in any medium, provided you give appropriate credit to the original author(s) and the source, provide a link to the Creative Commons license, and indicate if changes were made. 


\section{REFERENCES}

1. Chow K, Tong HHY, Lum S, Chow AHL. Engineering of pharmaceutical materials: an industrial perspective. J Pharm Sci. 2008;97:2855-77. https://doi.org/10.1002/jps.21212.

2. Rojas J, Buckner I, Kumar V. Co-processed excipients with enhanced direct compression functionality for improved tableting performance. Drug Dev Ind Pharm. 2012;38:1159-70. https://doi.org/10.3109/03639045.2011.645833.

3. Lopez FL, Ernest TB, Tuleu C, Gul MO. Formulation approaches to pediatric oral drug delivery: benefits and limitations of current platforms. Expert Opin Drug Deliv. 2015;12:1727-40. https://doi.org/10.1517/17425247.2015.1060218.

4. WHO. Report of the Informal Expert Meeting on Dosage Forms of Medicines for Children, 2008. http://www.who.int/ selection_medicines/committees/expert/17/application/paediatric/Dosage_form_reportDEC2008.pdf.

5. Walsh J, Ranmal SR, Ernest TB, Liu F. Patient acceptability, safety and access: a balancing act for selecting age-appropriate oral dosage forms for paediatric and geriatric populations. Int $\mathrm{J}$ Pharm. 2018;536:547-62. https://doi.org/10.1016/ j.ijpharm.2017.07.017.

6. S.R.S.R. Ranmal, F. O’Brien, F. Lopez, F. Ruiz, M. Orlu, C. Tuleu, et al., Methodologies for assessing the acceptability of oral formulations among children and older adults: a systematic review, Drug Discov Today. 2018;0. doi: 10.1016/ j.drudis.2018.01.038.

7. Walsh J, Cram A, Woertz K, Breitkreutz J, Winzenburg G, Turner $\mathrm{R}$, et al. Playing hide and seek with poorly tasting paediatric medicines: do not forget the excipients. Adv Drug Deliv Rev. 2014;73:14-33. https://doi.org/10.1016/j.addr.2014.02.012.

8. Kozarewicz P. Regulatory perspectives on acceptability testing of dosage forms in children. Int J Pharm. 2014;469:245-8. https:// doi.org/10.1016/j.ijpharm.2014.03.057.

9. EMA. Guideline on pharmaceutical development of medicines for paediatric use. 2013. http://www.ema.europa.eu/docs/en_GB/ document_library/Scientific_guideline/2013/07/WC500147002.pdf.

10. Gohel MC, Jogani PD. A review of co-processed directly compressible excipients. J Pharm Pharm Sci. 2005;8:76-93.

11. B.J. Bowles, K. Dziemidowicz, F.L. Lopez, M. Orlu, C. Tuleu, A.J. Edwards, et al., Co-processed excipients for dispersible tablets-Part 1: manufacturability. AAPS PharmSciTech. 2018. https://doi.org/10.1208/s12249-018-1090-4.

12. Kimura S, Uchida S, Kanada K, Namiki N. Effect of granule properties on rough mouth feel and palatability of orally disintegrating tablets. Int J Pharm. 2015;484:156-62. https:// doi.org/10.1016/j.ijpharm.2015.02.023.

13. FDA, Guidance for Industry: Orally disintegrating tablets, cent. Drug Eval Res. 2008. https://www.fda.gov/downloads/Drugs/ .../Guidances/ucm070578.pdf.

14. WHO. Development of paediatric medicines: points to consider in formulation, 2012.

15. WHO. Forty-fourth report of the WHO Expert Committee on specifi cations for pharmaceutical preparations. 2010. http:// www.who.int/medicines/publications/44threport/en/.

16. Brniak W, Jachowicz R, Pelka P. The practical approach to the evaluation of methods used to determine the disintegration time of orally disintegrating tablets (ODTs). Saudi Pharm J. 2015;23:437-43. https://doi.org/10.1016/j.jsps.2015.01.015.

17. Engelen L, Van Der Bilt A, Schipper M, Bosman F. Oral size perception of particles: effect of size, type, viscosity and method. J Texture Stud. 2005;36:373-86. https://doi.org/10.1111/j.17454603.2005.00022.x.

18. Imai E, Saito K, Hatakeyama M, Hatae K, Shimada A, Hatakeyama $\mathrm{H}$, et al. Effect of physical properties of food particles on the degree of graininess perveived in the mouth. J Texture Stud. 1998;30:59-88. https://doi.org/10.1111/j.17454603.1999.tb00202.x.

19. Fang L, Yin X, Wu L, He Y, He Y, Qin W, et al. Classification of microcrystalline celluloses via structures of individual particles measured by synchrotron radiation X-ray micro-computed tomography. Int J Pharm. 2017;531:658-67. https://doi.org/ 10.1016/j.ijpharm.2017.05.019.
20. Ek R, Alderborn G, Nyström C. Particle analysis of microcrystalline cellulose: differentiation between individual particles and their agglomerates. Int J Pharm. 1994;111:43-50. https://doi.org/ 10.1016/0378-5173(94)90400-6.

21. Yang Z, Swedlund P, Hemar Y, Mo G, Wei Y, Li Z, et al. Effect of high hydrostatic pressure on the supramolecular structure of corn starch with different amylose contents. Int J Biol Macromol. 2016;85:604-14. https://doi.org/10.1016/ j.ijbiomac.2016.01.018.

22. Parveen S, Rana S, Fangueiro R, Paiva MC. A novel approach of developing micro crystalline cellulose reinforced cementitious composites with enhanced microstructure and mechanical performance. Cem Concr Compos. 2017;78:146-61. https:// doi.org/10.1016/j.cemconcomp.2017.01.004.

23. Sun CC. Mechanism of moisture induced variations in true density and compaction properties of microcrystalline cellulose. Int J Pharm. 2008;346:93-101. https://doi.org/10.1016/ j.ijpharm.2007.06.017.

24. Thoorens G, Krier F, Leclercq B, Carlin B, Evrard B. Microcrystalline cellulose, a direct compression binder in a quality by design environment-a review. Int $\mathrm{J}$ Pharm. 2014;473:64-72. https://doi.org/10.1016/j.ijpharm.2014.06.055.

25. Kwak BM, Lee JE, Ahn JH, Jeon TH. Laser diffraction particle sizing by wet dispersion method for spray-dried infant formula. J Food Eng. 2009;92:324-30. https://doi.org/10.1016/ j.jfoodeng.2008.12.005.

26. Casian T, Bogdan C, Tarta D, Moldovan M, Tomuta I, Iurian S. Assessment of oral formulation-dependent characteristics of orodispersible tablets using texture profiles and multivariate data analysis. J Pharm Biomed Anal. 2018;152:47-56. https:// doi.org/10.1016/j.jpba.2018.01.040.

27. Moutasim MY, ElMeshad AN, El-Nabarawi MA. A pharmaceutical study on lornoxicam fast disintegrating tablets: formulation and in vitro and in vivo evaluation. Drug Deliv Transl Res. 2017;7:450-9. https://doi.org/10.1007/s13346-017-0367-6.

28. Rachid O, Rawas-Qalaji M, Simons FER, Simons KJ. Rapidlydisintegrating sublingual tablets of epinephrine: role of nonmedicinal ingredients in formulation development. Eur J Pharm Biopharm. 2012;82:598-604. https://doi.org/10.1016/ j.ejpb.2012.05.020.

29. Jamal MA, Rashad M, Khosa MK, Bhatti IA, Zia KM. Solution behaviour and sweetness response of d-mannitol at different temperatures. Food Chem. 2014;153:140-4. https://doi.org/ 10.1016/j.foodchem.2013.12.039.

30. Ohrem HL, Schornick E, Kalivoda A, Ognibene R. Why is mannitol becoming more and more popular as a pharmaceutical excipient in solid dosage forms? Pharm Dev Technol. 2014;19:257-62. https://doi.org/10.3109/10837450.2013.775154.

31. Engelen L, De Wijk RA, Van Der Bilt A, Prinz JF, Janssen AM, Bosman F. Relating particles and texture perception. Physiol Behav. 2005;86:111-7. https://doi.org/10.1016/ j.physbeh.2005.06.022.

32. Moqbel HA, ElMeshad AN, El-Nabarawi MA. Comparative study of different approaches for preparation of chlorzoxazone orodispersible tablets. Drug Dev Ind Pharm. 2016;9045:1-9. https://doi.org/10.1080/03639045.2016.1225753.

33. Jivraj M, Martini LG, Thomson CM. An overview of the different excipients useful for the direct compression of tablets. Pharm Sci Technol Today. 2000;3:58-63. https://doi.org/10.1016/ s1461-5347(99)00237-0.

34. Eadala P, Waud JP, Matthews SB, Green JT, Campbell AK. Quantifying the "hidden" lactose in drugs used for the treatment of gastrointestinal conditions. Aliment Pharmacol Ther. 2009;29:677-87. https://doi.org/10.1111/j.13652036.2008.03889.x.

35. Bharate SS, Bharate SB, Bajaj AN. Interactions and incompatibilities of pharmaceutical excipients with active pharmaceutical ingredients : a comprehensive review. J Excipients Food Chem. 2010;1:3-26.

36. Buck J, Huwyler J, Kühl P, Dischinger A. Pediatric dispersible tablets: a modular approach for rapid prototyping. Pharm Res. 2016;33:2043-55. https://doi.org/10.1007/s11095-016-1946-9.

37. R.G. Strickley, Q. Iwata, S. Wu, T.C. Dahl, Pediatric drugs-a review of commercially available oral formulations, Wiley Intersci. 2008;97: doi: 10.1002/jps. 
38. Venables R, Batchelor H, Hodson J, Stirling H, Marriott J. Determination of formulation factors that affect oral medicines acceptability in a domiciliary paediatric population. Int J Pharm. 2015;480:55-62. https://doi.org/10.1016/ j.ijpharm.2015.01.023.

39. Batchelor H, Venables R, Marriott J, Mills T. The application of tribology in assessing texture perception of oral liquid medicines. Int J Pharm. 2015;479:277-81. https://doi.org/10.1016/ j.ijpharm.2015.01.004.

40. R. Ternik, F. Liu, J.A. Bartlett, M. Khong, D. Cheng, T. Tan, et al., Assessment of swallowability and palatability of oral dosage forms in children: report from an M-CERSI pediatric formulation workshop. Int J Pharm 2017.

41. Mistry P, Batchelor H, Tibbins C. Design of tools to measure the acceptability of paediatric medicines. Int J Pharm. 2016;511:1143-4. https://doi.org/10.1016/j.ijpharm.2016.06.098.
42. Imai E, Hatae K, Shimada A. Oral perception of grittiness: effect of particle size and concentration of the dispersed particles. J Texture Stud. 1995;26:561-76.

43. Lopez FL, Bowles A, Gul MO, Clapham D, Ernest TB, Tuleu C. Effect of formulation variables on oral grittiness and preferences of multiparticulate formulations in adult volunteers. Eur J Pharm Sci. 2016;92:156-62. https://doi.org/10.1016/ j.ejps.2016.07.006.

44. Mishra B, Sharma G, Shukla D. Investigation of organoleptic characteristics in the development of soft chews of calcium carbonate as mineral supplement. Yakugaku Zasshi. 2009;129:1537-44. https://doi.org/10.1248/yakushi.129.1537.

45. F.L. Lopez, P. Mistry, H.K. Batchelor, J. Bennett, A. Coupe, T.B. Ernest, M. Orlu, C. Tuleu. Acceptability of placebo multiparticulate formulations in children and adults. Sci Rep. 2018;1-10. https://doi.org/10.1038/s41598-018-27446-6. 